\title{
Delivery across the blood-brain barrier: nanomedicine for glioblastoma multiforme
}

\author{
Lynn Jena $^{1} \cdot$ Emma McErlean ${ }^{1} \cdot$ Helen McCarthy ${ }^{1}$ (D \\ Published online: 14 November 2019 \\ (C) The Author(s) 2019
}

\begin{abstract}
The malignant brain cancer, glioblastoma multiforme (GBM), is heterogeneous, infiltrative, and associated with chemo- and radioresistance. Despite pharmacological advances, prognosis is poor. Delivery into the brain is hampered by the blood-brain barrier (BBB), which limits the efficacy of both conventional and novel therapies at the target site. Current treatments for GBM remain palliative rather than curative; therefore, innovative delivery strategies are required and nanoparticles (NPs) are at the forefront of future solutions. Since the FDA approval of Doxil® (1995) and Abraxane (2005), the first generation of nanomedicines, development of nano-based therapies as anti-cancer treatments has escalated. A new generation of NPs has been investigated to efficiently deliver therapeutic agents to the brain, overcoming the restrictive properties of the BBB. This review discusses obstacles encountered with systemic administration along with integration of NPs incorporated with conventional and emerging treatments. Barriers to brain drug delivery, NP transport mechanisms across the BBB, effect of opsonisation on NPs administered systemically, and peptides as NP systems are addressed.
\end{abstract}

Keywords BBB $\cdot$ Cell penetrating peptides $\cdot$ Drug delivery $\cdot$ GBM $\cdot$ Nanoparticle $\cdot$ RALA

$\begin{array}{ll}\text { Abbreviations } \\ \begin{array}{ll}\text { Au PENP } & \text { Polyethyleneimine-entrapped gold } \\ & \text { nanoparticles } \\ \mathrm{Au} & \text { Gold } \\ \mathrm{BBB} & \text { Blood-brain barrier } \\ \text { Bcl-2 } & \text { B cell lymphoma-2 } \\ \text { BCRP } & \text { Breast cancer resistance protein } \\ \text { BMEC } & \text { Brain microvascular endothelial cell } \\ \text { c(RGD) } & \text { Cyclic (arginine-glycine-aspartic acid) peptide } \\ \text { Chol-PC L-PEGylated cleavage lipopeptide } \\ \text { LNP }\end{array} \\ \text { CNS } & \text { Central nervous system } \\ \text { CPP } & \text { Cell penetrating peptide }\end{array}$

Helen McCarthy

h.mccarthy@qub.ac.uk

Lynn Jena

ljena01@qub.ac.uk

Emma McErlean

e.mcerlean@qub.ac.uk

1 School of Pharmacy, Queen's University Belfast, 97 Lisburn Road, Belfast, Northern Ireland BT9 7BL, UK
D M - P C L -Dimyristoyl anchored PEGylated MMPLNP cleavable lipopeptide

DSPE $\quad 1,2$ - D i s t e a r o y $1-\mathrm{s} n-\mathrm{g} l \mathrm{y} \mathrm{c}$ e r o - 3phosphoethanolamine

DTC Dithiolane-functionalized trimethylene carbonate

EB Evans blue

ECM Extracellular matrix

EPR Enhanced permeability and retention effect

FUS Focused ultrasound

GBM Glioblastoma multiforme

GFP Green fluorescent protein

GSH Glutathione

IL-13p IL-13 peptide

JCPyV John Cunningham virus

LNP Lipid nanoparticle

MGMT O6-Methylguanine methyltransferase

MI

Mechanical index

MMPs Metalloproteinases

MPS

MTX

NPs

PBCA Poly(n-butyl-2-cyanoacrylate)

PEG Poly(ethylene glycol) 


$\begin{array}{ll}\text { PEG-PCL } & \text { Poly(ethylene glycol)-poly( } \varepsilon \text {-caprolactone) } \\ \text { PEI } & \text { Polyethyleneimine } \\ \text { PE-PEG } & \text { DSPE-PEG2000 } \\ \text { P-gp } & \text { P-glycoprotein } \\ \text { pHA } & \text { p-Hydroxybenzoic acid } \\ \text { PTX } & \text { Paclitaxel } \\ \text { P T X - C 1 } & \text {-Paclitaxel cleavable liposomes } \\ \text { Lip } & \\ \text { RALA } & \text { Peptide with repeat units of arginine-alanine- } \\ & \text { leucine-alanine (R-A-L-A) } \\ \text { RCCM } & \text { Reversibly core-crosslinked micelles } \\ \text { RGD } & \text { Arginine-glycine-aspartic acid peptide } \\ \text { ROS } & \text { Reactive oxygen species } \\ \text { siRNA } & \text { Small interfering RNA } \\ \text { SLN } & \text { Solid lipid nanoparticle } \\ \text { STR } & \text { Steric acid } \\ \text { Tf } & \text { Transferrin } \\ \text { TfR } & \text { Transferrin receptor } \\ \text { t k - V L P s / Thymidine kinase-virus like particles/ } \\ \text { GCV } & \text { ganciclovir } \\ \text { TME } & \text { Tumour microenvironment } \\ \text { TMZ } & \text { Temozolomide } \\ \text { VLP } & \text { Virus-like particle }\end{array}$

\section{Introduction}

In 2018, malignancies of the brain and nervous system accounted for approximately $1.7 \%$ of all new cancer cases globally [1]. Although rare, cancers within the central nervous system (CNS) are associated with significant morbidity and mortality, representing an important clinical problem. In those affected, tumours can be classified into two groups: primary and metastatic tumours [2]. Primary tumours arise from residing tissue cells composed of glial or non-glial cells which develop on blood vessels, glands, and nerves [3]. Metastases in the brain commonly develop from distal primary malignancies including the lung and breast [4]. Up to $30 \%$ of breast cancer tumours metastasise to the brain and are associcated with extremely poor prognosis [5]. Primary and metastatic tumours equally pose extraordinary challenges, inherent to the site of origin, resulting in a poor drug response [6]. Due to the location, tumours are difficult to detect until patients become symptomatic. Patients usually present with partial or generalised seizures, headaches due to raised intracranial pressure, and nausea, resulting in diagnoses usually at a late stage of progression [3]. Glioblastoma multiforme (GBM) is a member of the glioma tumour group and is the most common and deadliest of tumours in adults, accounting for $52 \%$ of all primary brain tumours with an average survival rate of 15 months. It is classified as the most serious grade IV astrocytoma and develops from the lineage of star-shaped glial cells, called astrocytes, that support nerve cells $[6,7]$.
GBM is characterised by highly expressed inflammatory mechanisms and tumorigenic pathways [8]. An increase of cytokine production is observed during tumour development, leading to oncogenic changes in the cerebral microenvironment including aberrant microvasculature development and gradual infiltration of tumour cells into the perivasculature matrix [9]. In 2016, The Cancer Genome Atlas Research Network and World Health Organisation described several clinically significant molecular and phenotypical characteristics of GBM, enabling classification into various subtypes such as O6-methylguanine methyltransferase (MGMT), IDH, H3 Lys27Met, and 1p/19q codeletion status [10, 11].

The complex molecular heterogeneity and aggressive infiltrative growth of GBM necessitates the use of a multitargeted approach for optimal patient outcome. First-line treatment options in the management of GBM include maximal tumour resection, radiotherapy, and treatment with the chemotherapeutic alkylating agent, temozolomide (TMZ) [12, ]. Patient 2-year survival has increased to $26.4 \%$ for those receiving radiation and concomitant TMZ compared to those receiving radiation therapy alone, where survival rates are $10.4 \%[8$, 14]. However, response to conventional treatments is often poor and limited by inevitable tumour recurrence, due to extensive infiltration and rapid progression $[15,16]$. Surgery is dependent upon the location of the tumour; not all gliomas are amenable to resection, such as those located on the basal ganglia or the brain stem [17]. Surgery is followed by adjuvant radio- and chemotherapy in an attempt to destroy any residual cancerous cells. However, cytotoxic effects are observed in surrounding healthy tissue, which can severely impair quality of life [12]. Over $50 \%$ of patients do not respond to TMZ treatment, a consequence of MGMT overexpression. This DNA repair pathway is characteristic of GBM cells which abrogates the effects of TMZ [18]. Additionally, use of TMZ is commonly associated with significant dose-related toxicity and increased risk of bone marrow suppression.

Despite recent advances in molecular biology and current combination treatment strategies, survival rates are incredibly low [19]. Even with combination treatment strategies, residual cells become radio- and chemoresistant. Such cells have stemlike survival characteristics, leading to a $90 \%$ relapse rate [20, 21]. For patients in this situation, the outlook is bleak, with palliative treatment soon left as the only option [22]. The lack of successful treatment outcomes with conventional therapies coupled with the difficulty of drug delivery across the bloodbrain barrier (BBB) highlights the desperate need for research and development of novel therapies for the treatment of GBM. Ideally, development of brain tumour-targeted systemic delivery systems, which increase therapeutic accumulation specifically at the tumour site, with minimal toxicity in normal healthy tissue are required to improve brain tumour treatments. However, there are various barriers to overcome if this treatment strategy is to be successful. 


\section{The blood-brain barrier}

The brain is protected by the highly specialised BBB, which tightly regulates the transport of metabolically important molecules between systemic circulation and the brain (Fig. 1) [23-25]. The BBB possesses several layers, ultimately resulting in the production of a physical and enzymatic barrier with a restrictive role in the penetration of many compounds [26]. A layer of specialised brain microvascular endothelial cells (BMECs) acts as a barrier through continuous interaction with the surrounding cerebral neurovasculature to maintain homeostasis [23]. BMECs differ morphologically and metabolically from other mammalian capillary endotheliums, containing a higher concentration of mitochondria and an absence of fenestrations, forming a physical barrier in the form of tight junctions [26]. Tight junctions are hydrophilic channels $(\sim$ $0.8 \mathrm{~nm}$ in diameter) between two adjacent endothelial cells which inhibit paracellular transport of approximately $98 \%$ of small molecules and nearly $100 \%$ of macromolecules such as peptides and proteins, important in molecular signalling [27, 28]. In addition, transmembrane proteins including the zona occludens, claudins, and junctional adhesion molecules are distributed along the BBB and mediate the diffusion of small lipophilic molecular compounds, in addition to supporting brain blood vessel formation and integrity [29]. Several other layers exist between the circulatory system and the brain. The basement membrane is composed of type IV collagen and pericytes anchored by the end feet of astrocytes, whilst extracellular matrix $(\mathrm{ECM})$ proteins fibronectin and laminin surround the capillaries [30,31]. Therefore, therapeutically active moieties must possess carefully combined characteristics to enable passage across each layer of the BBB from systemic circulation. These properties determine which particles traverse the barrier and the rate of transport [30]. In an attempt to enhance delivery across the BBB, Wohlfart et al. utilised surfactants to alter the physicochemical properties of doxorubicin, forming negatively charged nanoparticles (NPs) $(-19$ $\pm 3 \mathrm{mV}$ ) less than $200 \mathrm{~nm}$ in hydrodynamic size [32]. Male Wistar rats were intravenously treated with doxorubicin solution in $1 \%$ polysorbate 80 , doxorubicin bound to $\operatorname{poly}(n$-butyl-2-cyanoacrylate) (PBCA) NPs, or doxorubicin bound to PBCA NPs coated with polysorbate 80 . Low concentrations of doxorubicin were detected in whole brain homogenates (up to $0.18 \mu \mathrm{g} / \mathrm{g}$ ) of the doxorubicin solution treatment group in comparison to doxorubicin PBCA NPs, where a maximum concentration of $1 \mu \mathrm{g} / \mathrm{g}$ was observed after $2 \mathrm{~h}$. Significantly higher doxorubicin concentrations were detected, at least 2.5fold higher in the doxorubicin bound PBCA NPs coated with polysorbate 80 treatment group at all time points compared to solution. Furthermore, higher and clinically relevant doxorubicin concentrations were detected in the brain parenchyma with surfactant-coated NPs compared to uncoated particles. This study highlights how the uptake and distribution profiles of therapeutics in the CNS can be controlled by engineering the physiochemical properties of the NP drug delivery system such as hydrophobicity, surface area, charge, and particle size.

\section{Transport across the BBB}

The BBB is a major barrier to the delivery of therapeutics for CNS disease [33]. Traditional drug delivery approaches to the brain include direct intracerebral injection and BBB disruption, employed to enhance drug delivery. Wu et al. utilised microbubbles which facilitate focused ultrasound (FUS) to transiently open the BBB through local cavitation [34]. Microbubbles were delivered intravenously into SpragueDawley rats with subsequent application of FUS at three mechanical index (MI) levels: $\mathrm{MI}=0.62,0.85$, and 1.38 .

Fig. 1 An overview of transport mechanisms across the bloodbrain barrier (BBB). The BBB is formed by tightly knit endothelial cells lining brain capillaries, restricting access to brain cells and facilitating entry of essential nutrients for normal metabolism. Tight regulation of the brain homeostasis results in the prevention of some small and large therapeutic drugs passively crossing the BBB, via transcellular and paracellular pathways. Thus, energydependent routes must be utilised, such as receptor-mediated transcytosis, adsorptive transcytosis, and transport proteins

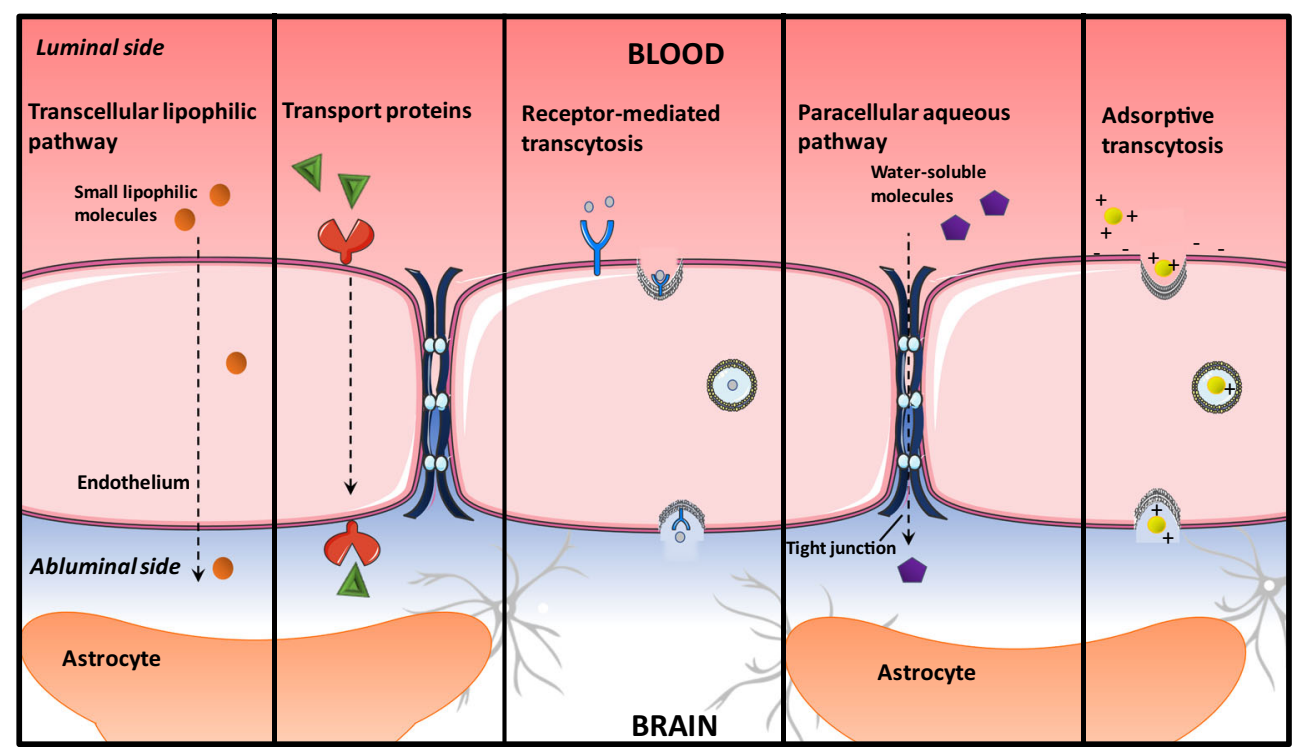


Following Evans blue (EB) leakage and staining to assess BBB opening, the authors report enhanced BBB opening and penetration with microbubbles and FUS. However, evidence of brain tissue damage was detected using magnetic resonance imaging in addition to haematoxylin and eosin staining. EB-stained areas of the brain were observed in those exposed to $0.85 \mathrm{MI}$ and $1.38 \mathrm{MI}$, suggesting FUS exposure levels should be carefully controlled for safety [34]. Another approach involves the co-administration of a therapeutic with hyperosmolar mannitol [35]. Co-administration with mannitol leads to the rapid diffusion of fluid from endothelial cells within the cerebrum into the vascular lumen, initiating transient opening of tight junctions [36, 37]. However, disrupting the BBB in this manner posses the risk of irreversible damage that necessitates strict control. Therefore, the use of endogenous transport mechanisms across the BBB is a more attractive entry route [38].

Identifying routes for less invasive, safer brain drug delivery and developing targeting strategies to evade biological barriers into the brain is an important area in drug delivery system design. In addition to the unique barriers which protect the brain, general barriers to systemic delivery include rapid opsonisation and clearance by the mononuclear phagocytic system (MPS), the tumour microenvironment (TME), the non-specific uptake, and the endosomal entrapment following cellular uptake [39]. Careful consideration and design are required to overcome each barrier, for the successful development of systemically delivered novel therapies targeting brain malignancies.

\section{Exploiting non-energy-dependent pathways}

The hydrophobic nature of the phospholipid bilayer membrane permits the passive diffusion of highly lipophilic, nonionised, low molecular weight $(<400 \mathrm{Da})$ entities across the BBB, through transcellular pathways [40]. This has major importance for systemic drug delivery, since the hydrophilic or hydrophobic nature of a therapeutic will impact on the specific transport mechanism utilised to cross the BBB. The modification of NPs to increase lipophilicity is a common strategy employed to dictate and enhance passive diffusion into the brain. Oldendorf et al. observed increased BBB permeability with increasing lipophilicity reported as $\log P$, which is the partition coefficient of a neutral molecule between aqueous and lipophilic phases at equilibrium [41]. ${ }^{14} \mathrm{C}$-labelled morphine, codeine, heroin, and methadone were administered into the carotid artery of Sprague-Dawley rats, and BBB uptake was measured. Heroin, with the highest $\log P$ value at 2.3 , resulted in higher BBB permeability compared to morphine and codeine with $\log P$ values at 0.99 and 1.2, respectively [40, 42].

Conversely, increasing hydrophobicity does not always result in increased entry to the brain. Kanazawa et al. assessed the effect of hydrophobicity on distribution within the brain through the modification of an arginine-rich peptide-based nanocarrier $(\mathrm{CH} 2 \mathrm{R} 4 \mathrm{H} 2 \mathrm{C})$ [43]. $\mathrm{CH} 2 \mathrm{R} 4 \mathrm{H} 2 \mathrm{C}$ peptide was modified with steric acid (STR) as a hydrophobic moiety (STR-CH2R4H2C) or poly(ethylene glycol)-poly( $\varepsilon$ caprolactone)-based block co-polymer (PEG-PCL) as a hydrophilic moiety (PEG-PCL-CH2R4H2C), using an Alexa fluorescently tagged model drug, Dextran (Alexa-dextran). Alexa-dextran was administered intranasally into male Sprague-Dawley rats, and distribution of the Alexa-dextran and STR-CH2R4H2C or PEG-PCL-CH2R4H2C/Alexa-dextran complexes was observed using in vivo fluorescence imaging. Authors found complexes were retained at the forebrain in the group receiving hydrophobic Alexa-dextran/STR$\mathrm{CH} 2 \mathrm{R} 4 \mathrm{H} 2 \mathrm{C}$, whilst in the group receiving hydrophilic PEGPCL-CH2R4H2C/Alexa-dextran fluorescence was immediately observed in the hindbrain and distributed across the brain tissue over time. In this study, the lipophilic drug did not not diffuse into the brain as effectively as its hydrophilic counterpart. It is possible that the highly lipophilic compounds were retained in the lipid layer, resulting in a poor therapeutic effect and the possibility of causing cellular toxicity through nonspecific uptake or removal by efflux transporters [40]. Therefore, a balance must be reached between lipophilicity and hydrophilicity to allow optimal therapeutic permeation and efficacy. CNS drug molecules should have an optimum octanol-water partition coefficient with an ideal $\log P$ value between 1.5 and 2.5 governing permeability across the BBB, when delivered systemically [40]. Although $\log P$ is one of the most important indicators of passive diffusion across the $\mathrm{BBB}$, it generally refers to the concentration ratio of unionised species of a compound. However, ionizable groups are present on $95 \%$ of formulated drug molecules. Many drug compounds are acidic or basic compounds, which become ionised to a certain degree in aqueous medium [44]. Subsequently, many drugs are unable to cross the BBB through passive diffusion, necessitating the exploitation of alternative uptake mechanisms.

\section{Exploiting energy-dependent pathways}

Essential hydrophilic compounds which lack BBB permeability such as insulin and glucose are transported across the BBB through energy-dependent receptor-mediated transport systems $[28,45]$. Several transport mechanisms exist, highlighted in Fig. 1, which facilitate the essential transport of molecules across the BBB. Facilitated diffusion, also known as carriermediated transport, allows solutes to bind to specific luminal and abluminal plasma membrane protein carriers facilitating movement along a concentration gradient [28]. Adsorptionmediated transcytosis is triggered by electrostatic interactions between positively charged moieties of cationic molecules and negatively charged membrane surface domains on the 
BBB, resulting in non-specific endocytosis [46]. Conversely, receptor-mediated transcytosis is highly specific and selective, involving ligand binding to a specific transmembrane receptor facilitating cellular internalisation. Receptor-mediated transport through the BBB is attractive in nanodelivery design due to the potential for active targeting and transport of a wide range of molecules following functionalisation with ligands for brain-specific receptors [46]. Gao et al. conjugated IL-13 peptide (IL-13p) onto PEG-PCL NPs (ILNPs) to specifically target the IL13R $\alpha 2$ receptor which is exclusively expressed by all cancerous cells [47]. The peptide ligand, IL-13p, has been found to possess cell penetrating characteristics which can increase specificity and facilitate cellular uptake by receptor-mediated endocytosis. Coumarin-6, a fluorescent model drug, was loaded into PEG-PCL NPs, and ILNPs were intravenously administered to U87 xenograft-bearing BALB/c nude mice. Tumours were excised and analysed by flow cytometry $2 \mathrm{~h}$ post-administration. NP tumour biodistribution showed that ILNP fluorescence was 2.96-fold higher than the PEG-PCL NP treatment group, highlighting the enhanced delivery of ILNPs through receptor targeting.

The transferrin receptor (TfR) is one of the most important and unique targets for exploiting receptor-mediated transport in GBM. Transferrin is a serum iron carrier protein which binds to the luminal transmembrane glycoprotein, transferrin receptor 1 (TfR1), thus regulating the uptake and transport of iron across the BBB for neural conductivity and metabolism [48]. Under normal physiological conditions, TfRs exclusively bind and enable entry of endogenous transferrin, whilst excluding many drugs and recombinant proteins [49]. TfRs are highly overexpressed by GBM tumour cells [50] and may be exploited as a target for systemic NP drug delivery, by raising antibodies against TfRs and the use of transferrin as a ligand-targeting moiety [49]. Friden et al. intravenously delivered methotrexate (MTX) across Sprague-Dawley rat BBB using anti-transferrin receptor monoclonal antibody (OX-26), to selectively target TfR-expressing cells [51]. Radio-labelled OX-26 was found to accumulate within the BBB, with the quantity of OX-26 in the capillaries decreasing over a $24-\mathrm{h}$ period. OX-26 and MTX conjugates were delivered intravenously, and marked accumulation of MTX within the brain parenchyma was observed compared to the capillary presence. Authors observed higher uptake of labelled antibody with OX-26-MTX conjugate $24 \mathrm{~h}$ post-injection than antibody alone $(0.44 \%$ and $0.27 \%$ of injected dose, respectively). Although small, these results suggest there is potential for the exploitation of the TfR as a selective drug delivery targeting receptor.

Kang et al. conjugated CRTIGPSVC (CRT) peptide, a peptide which mimics iron binding to a complex of transferrin (Tf)/TfR, to poly(ethylene glycol)-poly(L-lactic-co-glycolic acid) NPs (CRT-NPs). BALB/c nude mice bearing intracranial C6 glioma were treated with Coumarin-6-labelled NP, CRT-
NP, and Tf-NPs via tail vein injection. CRT-NP exhibited higher levels of penetration and accumulation at the tumour site compared to Coumarin-6-labelled NPs and Tf-NPs alone (2.41-fold and 1.43-fold change, respectively) [52], highlighting the potential of CRT peptide as a targeting ligand for enhanced drug delivery in GBM. However, effectiveness of targeting ligands will depend on receptor expression as which is variable depending on different tumour types and with stage of disease, necessitating a multitargeted approach.

\section{Drug resistance and the $\mathrm{BBB}$}

The activity of the BBB as an efflux pump is another major barrier to drug delivery in the brain. A poor clinical response is commonly observed in GBM due to the combination of poor drug delivery and tumour resistance over time [53]. Drug resistance is mediated by overexpression of efflux pump transporters, namely $\mathrm{ABC}$ transporter proteins $\mathrm{P}$-glycoprotein ( $\mathrm{P}$ $\mathrm{gp})$, breast cancer resistance protein (BCRP), and multidrug resistance-associated proteins, which are expressed by BBB cells [53]. The ATP-driven transporters are localised on the luminal and abluminal plasma membrane to function as unidirectional efflux pumps [54]. The most commonly characterised efflux transporter is P-gp, which utilises ATP to transport substrates against the concentration gradient into the systemic circulation, hampering the delivery of many small lipophilic molecules [55].

P-gp is involved in both acquired and intrinsic drug resistance, a major feature of GBM chemoresistance [56]. Intrinsic resistance indicates that before receiving chemotherapy, resistance-mediating factors pre-exist in the bulk of tumour cells that make the therapy ineffective. Acquired drug resistance can develop during treatment of tumours that were initially sensitive and can be caused by mutations arising during treatment, as well as through various other adaptive responses, such as increased expression of the therapeutic target and activation of alternative compensatory signalling pathways [57]. Anti-cancer drug resistance may occur through opposing drug-induced apoptosis and sequestration of anti-cancer mechanisms resulting in therapeutic failure [44]. Malignant cancer types and the BBB overexpress P-gp which interferes with ATP hydrolysis and lipid membrane integrity, reducing the availability of existing drug binding sites [5].

In recent times, a number of studies have shown that P-gp and BCRP transporters may work in synergy to inhibit the access of certain drugs into the CNS [54]. Laramy et al. examined the mechanism by which BBB efflux transporters limit CNS drug delivery by quantifying the rate and extent of CNS penetration of ponatinib, a tyrosine kinase inhibitor [58]. Authors delivered ponatinib intravenously and orally to mice with a range of genetic transporter knockouts: $M d r 1 a / b$ -/- (P-gp knockout), BCRP1-/- (BCRP knockout), Mdr1a/b -/- BCRP1-/- (triple knockout), and wild-type mice (Friend 
leukaemia virus strain B wild-type). Brain tissue and plasma samples were analysed using LC-MS/MS, and authors reported up to 15-fold higher brain-to-plasma ratios of ponatinib in the triple knockout mice compared to the wild-type mice. A higher concentration of ponatinib was also observed in both of the single knockout mouse models compared to wild type, although not to the extent of the triple knockout mice, suggesting a synergistic role of P-gp and BCRP on the BBB.

Knowledge of receptor and efflux pumps involved in drug resistant activity of the BBB may be exploited to overcome resistance and enhance therapeutic outcomes. Cavaco et al. utilised solid lipid NPs (SLNs) to deliver paclitaxel (PTX) to MDA-MB-436 breast cancer cells in vitro. Authors found cells treated with free PTX exhibited higher P-gp expression through upregulation of MDR1 mRNA cell levels, unlike those treated with SLNs [5]. The $\mathrm{IC}_{50}$ value observed for free PTX treated cells was $2.20 \mu \mathrm{g} / \mathrm{mL}$ compared to SLN-PTX and SLN-PTX-PEG at 1.48 and $1.51 \mu \mathrm{g} / \mathrm{mL}$, respectively, which may be attributed to higher P-gp expression resulting in increased free drug elimination post-uptake. This study demonstrates that delivery systems such as SLNs may efficiently evade P-gp resistance mechanisms through concealment of the drug cargo, and evidence of such systems in breast cancer models may also have application in the development of novel treatments for GBM.

Understanding the BBB structure and function allows for design of NP drug delivery systems that may exploit specific receptors to faciliate passage across the BBB, circumvent efflux, and potentially reduce problem drug resistance.

\section{Opsonisation and PEGylation}

Following systemic delivery, NPs are immediately exposed to harsh physiological conditions. Many NP formulations are rapidly sequestered by the MPS, which clears and degrades foreign material in circulation. Opsonisation usually occurs rapidly (within seconds) following entry into the blood stream and is triggered when complement proteins such as $\mathrm{C} 3, \mathrm{C} 4$, and $\mathrm{C} 5$ rapidly adsorb to the surface of the 'foreign' NP, forming a protein 'corona' [59]. The protein corona alters the surface of the NP within circulation, flagging it for recognition by opsonin serum proteins, including complement proteins, adhesion mediators (fibronectin), immunoglobulins, and coagulation factors [59-61]. This process leads to the subsequent clearance of NPs through phagocytosis by the MPS system. Certain properties will render a NP more susceptible to adsorption by complement proteins: cationic surface charge and hydrophobicity for example [62]. Neutral and hydrophilic particles undergo less opsonisation than hydrophobic particles; therefore, modification of steric and electrostatic interactions may help avoid clearance and increase therapeutic effectiveness [61].
One strategy employed to inhibit non-specific protein adsorption and reduce MPS clearance of nanomaterials is through PEGylation [63]. PEGylation involves surface modification with hydrophilic chains of poly(ethylene glycol) (PEG) to facilitate increased circulation time of NPs following systemic delivery. PEG is grafted to the surface of NPs, wherein hydrophilic ethylene glycol units form associations with water molecules, resulting in the formation of a hydrated layer. This creates a physical barrier which reduces the potential for electrostatic and hydrophobic interactions, hindering protein adsorption and subsequent clearance by the MPS [64, 65]. PEGylation shields the surface charge of a molecule, resulting in a more neutral surface charge as PEG content is increased [66]. Morshed et al. utilised PEGylated gold (Au) NPs conjugated to the TAT peptide to deliver doxorubicin to brain metastatic breast cancer cell lines MDA-MB-231-Br and CN34-Br [67]. Significant cellular uptake of PEGylated TAT$\mathrm{Au}$-doxorubicin was detected in vitro in both cell lines, compared to those treated with free doxorubicin at $99.5 \%$ and $18.4 \%$, respectively. PEGylated TAT-Au-doxorubicin NPs were subsequently delivered in vivo to female athymic nude mice bearing intracranial MDA-MB-231-Br xenografts. NPs were delivered through tail vein injections, and brain tissue was collected after $72 \mathrm{~h}$. NPs accumulated within tumour microsatellites in the brain parenchyma with no significant accumulation in normal tissue, resulting in a 39-day median survival rate in the PEGylated TAT-Au-Dox treatment group, compared to the free doxorubicin treatment groups at 25 days.

PEGylation may extend circulatory half-life, enhancing the exposure of the drug to the BBB for subsequent cellular uptake. In the TME, increased angiogenesis and aberrant endothelial formation results in fenestrated vasculature [39]. This confers an element of passive selectivity where NPs can extravasate into the tumour site as a result of the leaky vasculature. Over time, NPs accumulate in the TME, as the lack of lymphatic drainage results in enhanced retention [68]. This phenomenon is known as the enhanced permeability and retention effect (EPR) [69]. However, total dependence on the EPR effect for tumour targeting is not reliable. Solid and malignant tumours are highly heterogenous resulting in disparate tumour permeability, unfavourable for passive targeting. The EPR effect is thought to provide less than a 2-fold increase in drug delivery at tumour sites compared to healthy tissues. In the context of GBM, the surrounding brain parenchyma consists of a dense matrix which gives rise to elevated interstitial pressure, caused by increased vessel permeability and hyperperfusion, with an associated lack of lymphatic drainage within the brain $[38,70]$. Tumour growth produces intratumoural mechanical stress due to elevated cellular proliferation within a limited area termed 'Growth-induced solid stress' [71, 72]. Compression of stromal cells and physical deformation of vasculature cause alterations in gene expression, proliferation, and ECM architecture [71]. Therefore, in GBM, the 
surrounding dense matrix can act as a barrier for the adequate delivery of NP delivery systems at the target site.

Another design consideration in relation to PEGylation of NP systems is the 'charge shielding' nature of PEG, which may be problematic when considering passage through the BBB. It is well established that small hydrophobic molecules permeate through the BBB more effectively via passive diffusion [73]. Functionalisation of a hydrophobic NP with hydrophilic PEG chains will therefore impede any passive diffusion. Clinical translation so far has been impeded by low transfection efficiencies and a lack of stability in vivo. Although PEGylation is advantageous for circumvention of nonspecific MPS, it may negatively impact on cellular uptake. Hong et al. demonstrate the evasion of opsonisation through the development of PEGylated liposome-polycation-DNA NPs [74]. The liposomal system was composed of distearoyl phosphatidylcholine/cholesterol, and the authors examined the effect of PEG (MW $2000 \mathrm{Da}$ ) on pharmacokinetics and efficacy of liposomal doxorubicin in vivo. Male Balb/c mice bearing C-26 colon carcinoma cells upon the right hind limb were treated intravenously with free doxorubicin or liposomal doxorubicin preparations. Reduced liver uptake was evident with the PEGylated NPs, indicating avoidance of the MPS. However, the plasma area under the curve of PEGylated liposomal doxorubicin NPs was twice that of un-PEGylated liposomal doxorubicin at various dosages, and the group treated with un-PEGylated liposomal doxorubicin showed higher tumour doxorubicin concentrations. This study highlights the use of PEGylation for prolonging drug circulation but also indicates how this approach can inhibit drug uptake at the desired site.

Consequently, strategies have been employed to reduce the negative impact of PEG on NP cellular uptake. Cleavable PEG moieties have been developed to detach PEG upon arrival at the target tumour site in response to environmental factors, such as presence of specific enzymes. Metalloproteinases (MMPs) are a family of proteases commonly secreted by tumours, degrading the ECM, facilitating malignant growth and progression [75]. MMPs, such as MMP-2 and MMP-9, are overexpressed in many cancer types, including malignant brain cancers [76]. Bruun et al. formulated several lipid NPs (LNPs) less than $200 \mathrm{~nm}$ in size with differing PEGylated lipids, resulting in non-cleavable 1,2distearoyl-sn-glycero-3-phosphoethanolamine (DSPE)PEG2000 coated LNPs (PE-PEG-LNP) and cleavable LNP cholesterol anchored PEGylated cleavage lipopeptide (CholPCL-LNP) or dimyristoyl anchored PEGylated MMPcleavable lipopeptide (DM-PCL-LNP) PEG moieties. The cleavable PEG chain incorporated four glutamic acid residues in the PEGylated cleavable lipoprotein to shield the charge of the NP, essential for prolonged systemic circulation. LNP uptake was measured in b.End.3 brain endothelial and U87MG glioblastoma MMP-2/9 expressing cell lines. The presence of
MMPs was exploited to induce cleavage of the PEG motif prior to cell internalisation, leading to 10 -fold higher NP uptake in Chol-PCL-LNP and DM-PCL-LNP treated cells compared to PE-PEG-LNPs in vitro. GBM is often associated with an adverse inflammatory response caused by the upregulation of MMPs [77]. Kulkarni et al. synthesised a MMP-9-cleavable, PEGylated lipopeptide which formed nano-sized vesicles with the lipids 1-palmitoyl-2-oleoyl-sn-glycero-3phospho-choline, PEGylated 1-palmitoyl-2-oleoyl-snglycero-3-phosphoethanolamine lipid, and cholesterylhemisuccinate.

TME is often in a state of oxidative stress, resulting in elevated levels of glutathione (GSH), which has also been exploited in NP delivery systems. Nanovesicles were treated with GSH and recombinant human MMP-9 resulting in the removal of the PEG groups. The MMP-sensitive peptide bond was then cleaved, and the encapsulated contents released through disruption of the vesicle lipid bilayer [78]. pHsensitive cleavable motifs have also garnered interest as means of exploiting the TME. The extracellular environment of malignant tumours possesses an acidic $\mathrm{pH}$ 6.5-6.9 in contrast with normal tissue under physiological conditions (pH 7.2-7.4) [79]. Zhang et al. synthesised $\mathrm{pH}$-sensitive PTX cleavable liposomes (PTX-Cl-Lip) composed of PEG5K-Hydrazone-PE and DSPE-PEG2K-R8, forming PTX loaded particles $99.2-122.8 \mathrm{~nm}$ in size. Under the low extracellular $\mathrm{pH}$ conditions of the TME, PEG was cleaved leaving the $\mathrm{R} 8$ peptide exposed, mediating tumour internalisation. In vivo experiments were conducted using 4 T1 (breast cancer) tumour bearing Balb/c mice. PTX-ClLip treatment groups demonstrated good tumour targeting ability with tumour growth inhibition at $37.8-59.8 \%$ compared to free PTX and non-cleavable preparations where authors observed no evident tumour inhibition [80]. Therefore, with careful tailoring of the NP design, cellular uptake of systemically delivered NPs into the brain may be enhanced through the application of a cleavable PEG mechanism, to evade clearance through opsonisation and phagocytosis, whilst adapting to environmental changes to provide a targeted therapy [81].

\section{Emerging NP delivery systems across the BBB}

The ease of size, shape, and composition modification including loading potential of NPs makes them ideal delivery systems for both gene therapy and drug delivery. Advantages include small size and surface composition which allows interaction and penetration of cell membranes, binding and stabilisation of therapeutic agents, and escape from lysosomes after endocytosis. Such NPs will allow for increased specificity with the aim of enhancing therapeutic outcomes in GBM. A range of delivery systems including liposomes, proteins, 
and gold nanoparticles have been or are currently being investigated in clinical trials (Table 1), which highlight the potential for such technologies. However, as yet no NP formulation has received regulatory approval for treatment of GBM.

\section{Viral delivery vehicles}

Currently, delivery systems derived from naturally evolved viruses have been specifically utilised in the transport of gene-based therapeutics into GBM, transferring genetic material into host cells. Viral treatment modalities are based upon natural or engineered viral molecular biology with the aim of targeting oncogenic pathways [83]. Viral vectors are of interest in gliomas as tumours are nearly exclusively confined to the CNS and distant metastases are rare, which complements the potential for local intratumoural spread [84]. Most recently, Chao et al. employed the JC virus (JCPyV), known to naturally infect glial cells and oligodendrocytes causing fatal progressive multifocal leukoencephalopathy in AIDS patients [85]. U87MG cells were intracranially implanted into nude mice which were subsequently treated via tail vein injection with JCPyV virus-like particles (VLPs) delivering a green fluorescent protein (GFP) reporter gene as a control. Authors sought to determine if VLPs could deliver packaged herpes simplex virus thymidine kinase suicide gene in combination with ganciclovir (tk-VLPs/GCV). Subsequent analysis showed distinct GFP expression at the tumour site with no GFP expression elsewhere, and in mice treated with tkVLPs/GCV, tumour growth was significantly inhibited. VLPs were able to protect the therapeutic genes and mediate systemic delivery to the local tumour site [85].

However, despite promising delivery rates, there are many uncertainties about toxicity and immunogenicity in the clinical application of viral vectors [86]. Risks include excessive or persistent replication of attenuated vaccines and insertional mutagenesis where viral DNA becomes incorporated into the host genome. This may result in disrupted expression of tumour suppressor genes and/or activation of oncogenes, leading to a shift to malignant cells [87]. In recent times, regulatory authorities have placed rigorous health and environmental laws in place to ensure products are carefully assessed before entry into and during clinical development [88]. In addition, difficulty in large-scale production and limitation in size of cargo have slowed the progression of viral vectors [89].

\section{Non-viral delivery vehicles}

Non-viral vectors, such as lipids, polymer, metallic, magnetic, and peptide-based NPs have garnered much interest due to the potential to circumvent problems associated with viral vectors, and physiochemical versatility allows for careful tailoring of the NP surface for tumour targeting [90]. Such NPs represent a new generation of delivery systems. However, transfection rates with non-viral vectors still lag behind that of viral vectors and much work is still to be done to improve efficiency [91]. Peptide-based vectors are advantageous as they can be designed to mimic viral vector characteristics for effective cellular uptake and to increase the drug delivery of a wide range of macromolecules. They are biodegradable, can be modified to increase biocompatibility, and possess a large loading capacity.

\section{Peptide-based vectors}

Recently, interest in peptide-based vectors for nucleic acid and macromolecular delivery has increased, due to the ease in manufacturing and modification of the amino acid sequence for enhancing cell penetrating characteristics. Cell penetrating peptides (CPPs), first described in the 1980s, represent one of the most promising molecular tools for delivery of active biological molecules $[92,93]$. Such peptides are capable of facilitating the intracellular delivery of various therapeutic cargo, without the need for specialised receptors, resulting in enhanced therapeutic outcomes.

One of the first CPPs discovered was Tat peptide (GRKKRRQRRR), derived from the transactivator of transcription from HIV-1 [94]. Tat is an arginine-rich, cationic peptide capable of delivering various types of cargo into a range of cell types. It is now well established that the strong cell penetrating activity of Tat is due to arginine residues, which bind anionic nucleic acid cargo and interact with anionic cell membranes, facilitating cellular uptake [95]. Mitchell et al. compared the uptake efficiencies of cationic poly-lysine, poly-arginine, and poly-histidine and found arginine was significantly more effective for cell penetration than the other cationic residues [96]. The superior activity of arginine is credited to the guanidinium headgroup which forms bidentate hydrogen bonds with anionic heparan sulphate proteoglycan components of the phospholipid bilayer, a crucial step in the initiation of cellular uptake [97].

However, CPPs may not rely solely on a cationic nature for cellular uptake. Penetratin, derived from the third helix of the homeodomain of Antennapedia named Penetratin (RQIKIYFQNRRMKWKK), is an example of an amphipathic $\alpha$-helical CPP where separation of hydrophobic and hydrophilic residues allows interaction with the hydrophobic domain of the phospholipid bilayer, facilitating passage into the cytoplasmic intracellular compartment [98]. The exact uptake mechanism of CPPs has yet to be fully elucidated; however, several types of endocytosis have been proposed such as caveolae-mediated endocytosis, macropinocytosis, and clathrin-mediated endocytosis. Despite the lack of complete understanding of the mechanisms of uptake, CPPs provide an alternative option in CNS drug delivery, offering negligible toxicity and immunogenicity compared to viral vectors. 
Table 1 Overview of NP delivery systems in clinical trials for glioblastoma multiforme [82]

\begin{tabular}{llll}
\hline NP delivery system & Intervention & $\begin{array}{l}\text { Drug name } \\
\text { (active agent) }\end{array}$ & Rationale
\end{tabular}$\quad \begin{aligned} & \text { Phase } \\
& \begin{array}{l}\text { National } \\
\text { clinical trial } \\
\text { identifier } \\
\text { (NCT) }\end{array}\end{aligned}$

\begin{tabular}{|c|c|c|c|c|c|c|}
\hline Liposome & $\begin{array}{l}\text { A catheter will be placed } \\
\text { within the tumour using } \\
\text { stereotactic guidance. } \\
\text { 186Rhenium } \\
\text { nanoliposomes (186RNL) } \\
\text { will be infused through } \\
\text { the catheter at a } \\
\text { predetermined dose. } \\
\text { Spectroscopic imaging } \\
\text { will then be obtained at } \\
\text { predefined time points to } \\
\text { visualise the distribution } \\
\text { profile of the 186RNL } \\
\text { and calculate the retained } \\
\text { dose within the tumour. } \\
\text { Patients will be monitored } \\
\text { for evidence of toxicity } \\
\text { and response for up to } \\
90 \text { days. }\end{array}$ & $\begin{array}{l}\text { Rhenium } \\
\text { (rhenium-186 } \\
\text { (186-Re), a } \\
\text { reactor } \\
\text { produced } \\
\text { isotope }\end{array}$ & $\begin{array}{l}\text { Radiation is part of the } \\
\text { conventional treatment of } \\
\text { glioblastoma, although it } \\
\text { is limited by toxicity at } \\
\text { higher doses. Packaging } \\
\text { radioactive isotopes in } \\
\text { nanoparticle formulation } \\
\text { may allow for delivery of } \\
\text { increased doses of } \\
\text { radiation to the brain } \\
\text { tumour site with reduced } \\
\text { toxicity. }\end{array}$ & $1 / 2$ & NCT01906385 & $\begin{array}{l}\text { Ongoing-January } \\
2020\end{array}$ \\
\hline Liposome & $\begin{array}{l}\text { The study is conducted to } \\
\text { determine the efficacy and } \\
\text { safety of IV SGT-53 and } \\
\text { standard oral } \\
\text { temozolomide in } \\
\text { combination in patients } \\
\text { with confirmed } \\
\text { glioblastoma who have } \\
\text { proven tumour recurrence } \\
\text { or progression. Surgical } \\
\text { resection occurs at day } 0 \text {. } \\
\text { At days } 14-21 \text {, SGT-53, } \\
\text { at } 3.6 \text { mg DNA per } \\
\text { infusion, will be } \\
\text { administered twice per } \\
\text { week for } 3 \text { weeks. TMZ } \\
\text { will be administered } \\
\text { orally on days } 9-13 \text { of } \\
\text { each cycle. }\end{array}$ & $\begin{array}{l}\text { Temozolomide } \\
\text { and SGT-53 } \\
\text { (normal } \\
\text { human wild } \\
\text { type p53 } \\
\text { DNA } \\
\text { sequence) }\end{array}$ & $\begin{array}{l}\text { Many tumours } \\
\text { characteristically display } \\
\text { loss of p53 suppressor } \\
\text { function. SGT-53 delivery } \\
\text { aims to restore wild-type } \\
\text { function of p53 to regulate } \\
\text { cell apoptosis, cell cycle } \\
\text { checkpoints, DNA repair, } \\
\text { and angiogenesis. }\end{array}$ & 2 & NCT02340156 & $\begin{array}{l}\text { Ongoing-December } \\
2019\end{array}$ \\
\hline Gold & $\begin{array}{l}\text { Patients receive NU-0129 IV } \\
\text { over } 20-50 \text { min and } \\
\text { undergo standard of care } \\
\text { tumour resection within } \\
8-48 \mathrm{~h} \text {. Subsequent } \\
\text { follow-ups occur at } 7,14 \text {, } \\
21 \text {, and } 28 \text { days and then } \\
\text { every } 84 \text { days for up to } \\
2 \text { years. }\end{array}$ & $\begin{array}{l}\text { NU-0129 } \\
\text { (spherical } \\
\text { nucleic acid } \\
\text { (SNA) } \\
\text { arranged on } \\
\text { the surface of } \\
\text { a spherical } \\
\text { Au NP) }\end{array}$ & $\begin{array}{l}\text { NU-0129 is transported } \\
\text { across the BBB where } \\
\text { once it reached the TME; } \\
\text { SNA targets the Bcl2L12 } \\
\text { gene, associated with } \\
\text { GBM tumour growth. } \\
\text { This gene in responsible } \\
\text { for inhibition of } \\
\text { apoptosis, promoting } \\
\text { tumour growth. }\end{array}$ & $\begin{array}{l}\text { Early } \\
\text { ph- } \\
\text { ase } \\
1\end{array}$ & NCT03020017 & Ongoing-July 2022 \\
\hline Albumin & $\begin{array}{l}\text { ABI-009 will be } \\
\text { administered IV as a } \\
\text { single agent or in } \\
\text { combination with } \\
\text { standard therapies such as } \\
\text { TMZ, TMZ + radiation, } \\
\text { bevacizumab, and } \\
\text { lomustine. The study will } \\
\text { assess number of people } \\
\text { with treatment-related } \\
\text { adverse events, }\end{array}$ & $\begin{array}{l}\text { ABI-009 } \\
\quad \text { (nab-- } \\
\text { rapamycin) }\end{array}$ & $\begin{array}{l}\text { The macrolide antibiotic } \\
\text { rapamycin bound to NP } \\
\text { albumin is delivered to } \\
\text { patients with the aim of } \\
\text { stimulating } \\
\text { immunosuppressant, } \\
\text { antiangiogenic, and } \\
\text { antineoplastic activities. } \\
\text { Efficacy is mediated } \\
\text { through rapamycin } \\
\text { binding to the }\end{array}$ & 2 & NCT03463265 & Ongoing-June 2021 \\
\hline
\end{tabular}


Table 1 (continued)

\begin{tabular}{|c|c|c|c|c|c|c|}
\hline NP delivery system & Intervention & $\begin{array}{l}\text { Drug name } \\
\text { (active agent) }\end{array}$ & Rationale & Phase & $\begin{array}{l}\text { National } \\
\text { clinical trial } \\
\text { identifier } \\
\text { (NCT) }\end{array}$ & Completion date \\
\hline & $\begin{array}{l}\text { progression free survival, } \\
\text { and overall survival. }\end{array}$ & & $\begin{array}{l}\text { immunophilin FK binding } \\
\text { protein-12 (FKBP-12). }\end{array}$ & & & \\
\hline $\begin{array}{l}\text { Convection-enhanced } \\
\text { delivery (CED) }\end{array}$ & $\begin{array}{l}\text { The aim of the study is to } \\
\text { determine the safety and } \\
\text { tolerability of repeated } \\
\text { administration of } \\
\text { MTX110 co-infused with } \\
\text { gadoteridol given by } \\
\text { intratumoural } \\
\text { convection-enhanced } \\
\text { delivery (CED) in } \\
\text { children with newly } \\
\text { diagnosed diffuse intrinsic } \\
\text { pontine glioma (DIPG). } \\
\text { Participants receive NP } \\
\text { formulation on day } 1 \text { or } \\
\text { days } 1 \text { and } 2 \text { as } \\
\text { determined by dose level. } \\
\text { Courses repeat every } \\
4-8 \text { weeks for up to } \\
24 \text { months. }\end{array}$ & $\begin{array}{l}\text { MTX110 } \\
\text { (panobinosta- } \\
\text { t) }\end{array}$ & $\begin{array}{l}\text { Panobinostat has } \\
\text { demonstrated preclinical } \\
\text { efficacy against DIPG. } \\
\text { However, panobinostat is } \\
\text { unable to cross the BBB } \\
\text { as a single agent. CED is a } \\
\text { novel drug delivery } \\
\text { technique that bypasses } \\
\text { the BBB - targeted } \\
\text { delivery occurs when } \\
\text { catheters are placed } \\
\text { within the CNS. A bulk } \\
\text { flow mechanism is } \\
\text { created by a small } \\
\text { pressure gradient infusing } \\
\text { the drug formulation } \\
\text { through the catheter to } \\
\text { target the brain. }\end{array}$ & $1 / 2$ & NCT03566199 & $\begin{array}{l}\text { Ongoing-September } \\
2020\end{array}$ \\
\hline
\end{tabular}

Naturally occurring peptide sequences such as TAT and Penetratin have guided the development of bio-inspired multifunctional synthetic peptides which possess all the characteristics required for maximal cellular uptake. Rational design allows the development of CPPs with specific amino acid residues and structures to augment peptide activity [93]. GALA (WEAALAEALAEALAEHLAEALAEALEALAA) is a fusogenic, $\alpha$-helical peptide which was designed as a simple model of a viral fusion peptide sequence [99]. However, GALA is anionic in nature and does not bind to or condense nucleic acids [97, 99]. Consequently, KALA (WEAKLAKALAKALAKHLAKALAKALKACEA) was developed, where the anionic glutamic residues were replaced with cationic lysine. The resultant cationic nature of KALA facilitates interaction with anionic nucleic acids and enhanced cellular uptake due to interaction with anionic cell membranes. Despite this, arginine has proved to be a much superior amino acid than lysine with improved DNA condensing ability and strong cell penetrating ability [95]. RALA (WEARLARALARALARHLARALARALRACEA) was developed by McCarthy et al. by substituting arginine residues in place of lysine, resulting in enhanced nucleic acid condensation, improved cell penetration, and minimal cytotoxicity [97]. The sequence of RALA comprises repeat units of arginine-alanine-leucine-alanine (R-A-L-A) which confer secondary amphipathicity due to separation of the cationic hydrophilic arginine and hydrophobic leucine residues when the peptide is folded in an alpha helix. The overall combination of cationicity and amphipathicity allows RALA to complex and condense anionic nucleic acids and small molecules through electrostatic interactions into NPs $(<200 \mathrm{~nm}$ in diameter). The therapeutic cargo is protected from degradation when delivered systemically and facilitates efficient intracellular delivery. The cationic nature of RALA allows interaction with the slightly negative BBB, becoming embedded within the phospholipid bilayer where NPs are taken up via endocytic mechanisms [97].

Following endocytosis, NPs are generally held within acidic endosomes. At the low $\mathrm{pH}$ of the mature endosome $(\mathrm{pH}<$ 5), many drug molecules become degraded, hindering the accumulation of therapeutic concentrations at the active site [100]. However, the $\mathrm{pH}$-responsive fusogenic activity of RALA enables the release of complexed cargo before it can be degraded (Fig. 2) [97]. RALA has been utilised to deliver a range of cargo including plasmids encoding reporter genes, small interfering RNA (siRNA), messenger RNA (mRNA), and therapeutic plasmids, in addition to anionic small molecule (such as bisphosphonates) and incorporation into polymeric microneedles [97, 101-105]. This demonstrates the immense potential of RALA as a CNS delivery agent, highlighting the versatility of fusogenic peptides in general. The unique combination of cationicity, amphipathicity, and $\mathrm{pH}$ responsive fusogenicity makes RALA an exciting candidate for multifunctional drug delivery across the BBB. 


\section{Multifunctional drug delivery systems}

The complex nature of targeted systemic drug delivery requires the NP to overcome numerous barriers and challenges and ultimately requires a multifunctional system. Engineering strategies involving PEGylation and targeting ligands have potential to overcome some specific barriers, but a multifunctional system must have the capacity to overcome all the barriers for successful drug delivery. NPs have been functionalised to facilitate cargo transport to target organs, including the brain, making way for a pivotal development in drug delivery. Fang et al. developed cRGD-functionalized, reversibly crosslinked, multifunctional, biodegradable doxorubicin micelles based on PEG-PCL (cRGD-RCCMs) [106]. Particles were $<200 \mathrm{~nm}$ in hydrodynamic size, designed to enhance in vivo stability through increased blood circulation time and intracellular release in GBM. Crosslinking synthesis occurred using the redox-sensitive monomer dithiolanefunctionalized trimethylene carbonate (DTC) via ringopening polymerisation which is proposed to decrosslink within the TME [106]. In GBM, chronic inflammation within brain tissue induces oxidative stress resulting in an imbalance of redox homeostasis. A high metabolic rate during tumourigenesis leads to increased basal levels of reactive oxygen species (ROS). ROS act as chemical intermediaries to create an immunosuppressive environment through the regulation of signal transduction to protect malignant GBM cells from apoptosis []. This mechanism was exploited to decrosslink DTC monomers once NPs reached TME, whilst cRGD peptide is proven to enhance uptake into malignant cells, providing a targeted effect $[106,108]$. Authors found doxorubicin-cRGD-RCCMs enhanced intravenous doxorubicin delivery in vivo to U87MG-bearing nude mice where doxorubicin distribution in the tumour and major organs was quantified by fluorometry. Interestingly, doxorubicin-cRGDRCCM-treated mice displayed a tumour doxorubicin level of $7.7 \% \mathrm{ID} / \mathrm{g}$ (injected dose per gramme of tissue), which was significantly higher than both doxorubicin-RCCMs and doxorubicin-liposomal particles, each with less than $2.5 \%$ $\mathrm{ID} / \mathrm{g}$. It is evident cRGD-RCCMs mediated potent and targeted GBM therapy, providing significantly improved treatment efficacy than non-crosslinked micellar doxorubicin and pegylated liposomal doxorubicin controls [80].

Multifunctional NP delivery systems have also been utilised in the delivery of genetic material as potential GBM treatment. Kong et al. described the use of polyethyleneimine (PEI)-entrapped Au NPs (Au PENPs) modified with an arginine-glycine-aspartic (RGD) peptide with a PEG spacer as a vector for anti-apoptotic defence protein $\mathrm{B}$ cell lymphoma-2 (Bcl-2) siRNA delivery to GBM cells. Authors
Fig. 2 Schematic representation of proposed RALA NP endosomal escape mechanism. a The overall cationic and amphipathic nature of RALA facilitates electrostatic interaction with the slight negative charge of the cell lipid bilayer. b RALA is transported into the intracellular compartment through endocytic mechanisms. $\mathbf{c}$ Under the acidic $\mathrm{pH}$ of the endosome, RALA undergoes conformational change within the endosome eventually leading to release of the complexed cargo into the intracellular matrix where it can exert an effect

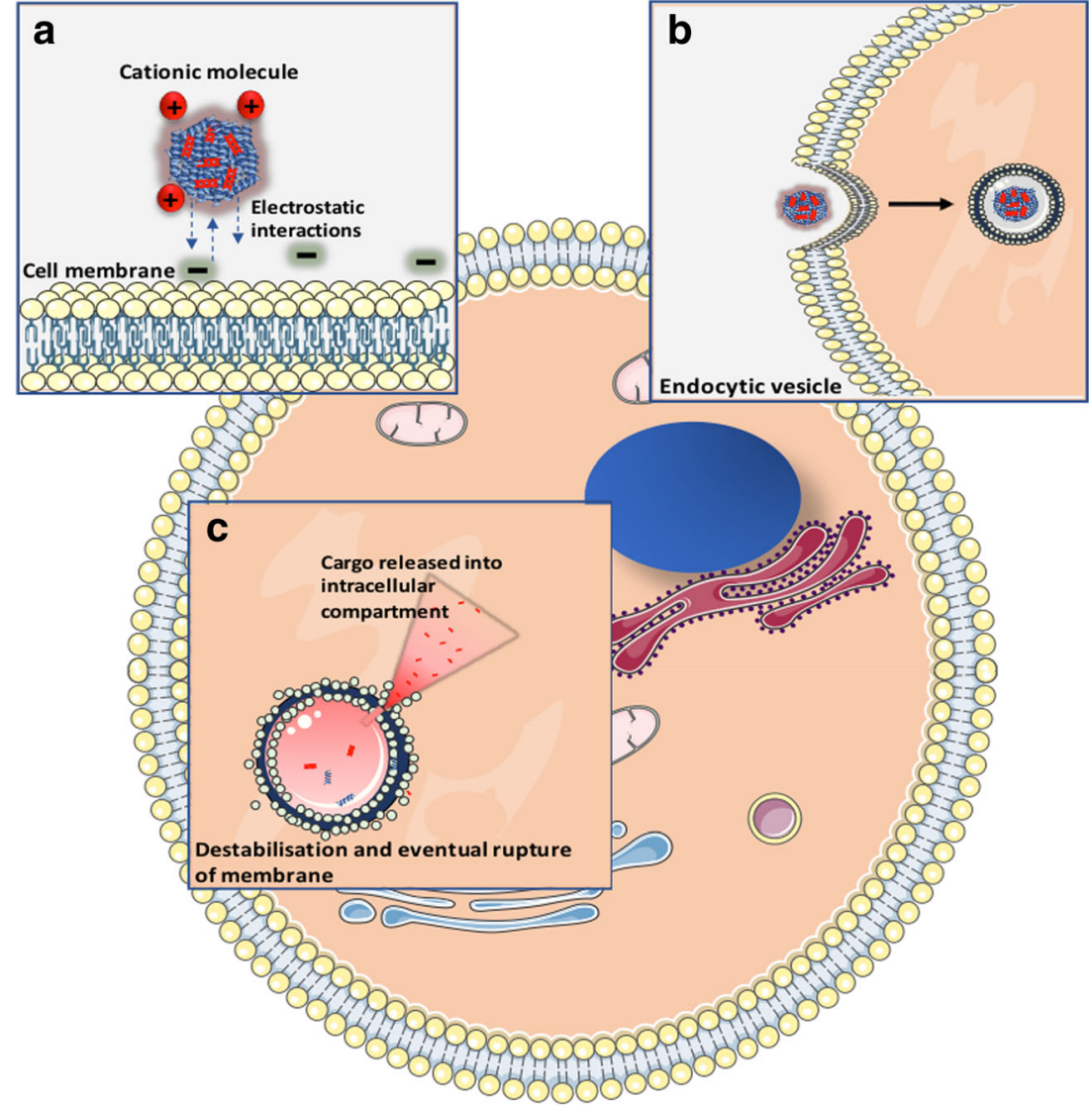


reported gene silencing up to $50.8 \% \mathrm{Bcl}-2$ protein expression in vivo when $\mathrm{Au}-\mathrm{PENPs}$ were delivered to $\mathrm{BALB} / \mathrm{c}$ nude mice bearing U87MG xenografts. It was proposed the modified RGD peptide-mediated receptor mediated uptake through binding to the $\alpha \mathrm{v} \beta 3$ integrin receptor expressed on the surface of cancer cells whilst formed PEGylated PEI was used as a template in Au NP synthesis [109].

These studies highlight the future potential of multifunctional NP delivery systems which can respond to the tumour microenvironment to provide for the targeted treatment of GBM. However, careful consideration should be taken in NP design to ensure functionality is not compromised with increasing complexity. Further research needs to be conducted on the industrial upscale of NP technology with regard to storage, safety, and stability. Future considerations must also include the cost/benefit ratio of such modifications, since the addition of each new functionality increases complexity of production and cost, which can also result in regulatory barriers.

\section{Conclusion}

Novel therapies aim to circumvent many of the barriers posed in GBM, namely increased half-life, delivery across the BBB and selective uptake of the therapeutic at the tumour site. The use of endogenous transporters has considerable potential in transporting a wide variety of molecules across the BBB. Ultimately, the accelerated development of nanodelivery systems into clinical stages highlights the potential of NPs as anticancer therapies reaching the patient. The introduction of NP systems as treatment strategies in GBM provides us with the tools to improve drug delivery of a wide range of therapeutic agents, efficacy, and ultimately patient outcomes.

\section{Compliance with ethical standards}

Conflict of interest The authors declare that they have no conflict of interest.

Open Access This article is distributed under the terms of the Creative Commons Attribution 4.0 International License (http:// creativecommons.org/licenses/by/4.0/), which permits unrestricted use, distribution, and reproduction in any medium, provided you give appropriate credit to the original author(s) and the source, provide a link to the Creative Commons license, and indicate if changes were made.

\section{References}

1. Ferlay J, Colombet M, Soerjomataram I, Mathers C, Parkin DM, Piñeros $\mathrm{M}$, et al. Estimating the global cancer incidence and mortality in 2018: GLOBOCAN sources and methods. Int J Cancer. 2019;144(8):1941-53.
2. Tang V, Rathbone M, Park Dorsay J, Jiang S, Harvey D. Rehabilitation in primary and metastatic brain tumours. J Neurol. 2008;255(6):820-7.

3. Neurological Conditions and Treatments: Brain Tumours [Internet]. American Association of Neurological Surgeons. [cited 2019 May 30]. Available from: https://www.aans.org/en/Patients/ Neurosurgical-Conditions-and-Treatments/Brain-Tumors

4. Rahmathulla G, Toms SA, Weil RJ. The molecular biology of brain metastasis. J Oncol. 2012;2012:1-16.

5. Haar CP, Hebbar P, Iv GCW, Das A, William A, Iii V, et al. drug resistance in glioblastoma: a mini review. Neurochem Res. 2012;37(6):1192-200.

6. Tumor Types: Understanding Brain Tumors [Internet]. National Brain Tumour Society. [cited 2019 Jun 30]. Available from: https://braintumor.org/brain-tumor-information/understandingbrain-tumors/tumor-types/

7. American Association of Neurological Surgeons. Glioblastoma multiforme - symptoms, diagnosis and treatment options [Internet]. 2019 [cited 2019 Sep 3]. Available from: https://www. aans.org/Patients/Neurosurgical-Conditions-and-Treatments/ Glioblastoma-Multiforme

8. Alifieris C, Trafalis DT. Glioblastoma multiforme: pathogenesis and treatment. Pharmacol Ther [Internet]. 2015;152:63-82 Available from: http://linkinghub.elsevier.com/retrieve/pii/ S0163725815000960.

9. Hambardzumyan D, Bergers G. Glioblastoma: defining tumor niches. Trends Cancer. 2015;1(4):252-65.

10. Louis DN, Perry A, Reifenberger G, von Deimling A, FigarellaBranger D, Cavenee WK, et al. The 2016 World Health Organization classification of tumors of the central nervous system: a summary. Acta Neuropathol. 2016;131(6):803-20.

11. Lapointe S, Perry A, Butowski NA. Primary brain tumours in adults. Lancet. 2018;392(10145):432-46.

12. Urbanska K, Sokolowska J, Szmidt M, Sysa P. Glioblastoma multiforme - an overview. Wspolczesna Onkol. 2014;18(5):30712.

13. Perry J, Okamoto M, Guiou M, Shirai K, Errett A, Chakravarti A. Novel therapies in glioblastoma. Neurol Res Int. 2012;2012: 428565-79.

14. Affronti ML, Heery CR, Herndon JE, Rich JN, Reardon DA, Desjardins A, et al. Overall survival of newly diagnosed glioblastoma patients receiving carmustine wafers followed by radiation and concurrent temozolomide plus rotational multiagent chemotherapy. Cancer. 2009;115(15):3501-11.

15. Iacob G, Dinca EB. Current data and strategy in glioblastoma multiforme. J Med Life [Internet]. 2009;2(4):386-93 Available from: http://www.pubmedcentral.nih.gov/articlerender.fcgi? artid $=3019011 \&$ tool $=$ pmcentrez\&rendertype $=$ abstract.

16. Vigneswaran K, Neill S, Hadjipanayis CG. Beyond the World Health Organization grading of infiltrating gliomas: advances in the molecular genetics of glioma classification. Ann Transl Med. 2015;3(7):95.

17. Hanif F, Muzaffar K, Perveen K, Malhi SM, Simjee SU. Glioblastoma multiforme: a review of its epidemiology and pathogenesis through clinical presentation and treatment. Asian Pac J Cancer Prev. 2017;18(1):3-9.

18. Lee SY. Temozolomide resistance in glioblastoma multiforme. Genes Dis. 2016;3(3):198-210.

19. Thakkar JP, Dolecek TA, Horbinski C, Ostrom QT, Lightner DD, Barnholtz-Sloan JS, et al. Epidemiologic and molecular prognostic review of glioblastoma. Cancer Epidemiol Biomark Prev. 2014;23(10):1985-96.

20. Choucair AK, Levin VA, Gutin PH, Davis RL, Silver P, Edwards MSB, et al. Development of multiple lesions during radiation therapy and chemotherapy in patients with gliomas. J Neurosurg. 1986;65(5):654-8. 
21. Chesler DA, Berger MS, Quinones-Hinojosa A. The potential origin of glioblastoma initiating cells. Front Biosci. 2012;S4(1): 190.

22. Sizoo EM, Braam L, Postma TJ, Pasman HRW, Heimans JJ, Klein $\mathrm{M}$, et al. Symptoms and problems in the end-of-life phase of highgrade glioma patients. Neuro-Oncology. 2010;12(11):1162-6.

23. Van Tellingen O, Yetkin-Arik B, De Gooijer MC, Wesseling P, Wurdinger T, De Vries HE. Overcoming the blood-brain tumor barrier for effective glioblastoma treatment. Drug Resist Updat. 2015;19:1-12.

24. Reichel A. The role of blood-brain barrier studies in the pharmaceutical industry. Curr Drug Metab. 2006;7(2):183-203.

25. Chen Y, Liu L. Modern methods for delivery of drugs across the blood-brain barrier. Adv Drug Deliv Rev. 2012;64(7):640-65.

26. Abbott NJ, Friedman A. Overview and introduction: the bloodbrain barrier in health and disease. Epilepsia. 2012;53(6):1-6.

27. Barua S, Mitragotri S. Challenges associated with penetration of nanoparticles across cell and tissue barriers: a review of current status and future prospects. Nano Today. 2014;9(2):223-43.

28. Pardridge WM. Drug transport across the blood-brain barrier. J Cereb Blood Flow Metab. 2012;32(11):1959-72.

29. Haseloff RF, Dithmer S, Winkler L, Wolburg H, Blasig IE. Transmembrane proteins of the tight junctions at the blood-brain barrier: structural and functional aspects. Semin Cell Dev Biol. 2015;38:16-25.

30. Burdo JR, Antonetti DA, Wolpert EB, Connor JR. Mechanisms and regulation of transferrin and iron transport in a model bloodbrain barrier system. Neuroscience. 2003;121(4):883-90.

31. Daneman R, Prat A. The blood-brain barrier. Cold Spring Harb Perspect Biol. 2015;7(1):1-23.

32. Wohlfart S, Khalansky AS, Gelperina S, Begley D, Kreuter J. Kinetics of transport of doxorubicin bound to nanoparticles across the blood-brain barrier. J Control Release. 2011;154(1):103-7.

33. Nam JY, de Groot JF. Treatment of glioblastoma multiforme. Am Soc Clin Oncol. 2017;13(10):629-638.

34. Wu SK, Chu PC, Chai WY, Kang ST, Tsai CH, Fan CH, et al. Characterization of different microbubbles in assisting focused ultrasound-induced blood-brain barrier opening. Sci Rep. 2017;7(October 2016):1-11.

35. Brown RC, Egleton RD, Davis TP. Mannitol opening of the blood-brain barrier: Regional variation in the permeability of sucrose, but not $86 \mathrm{Rb}+$ or albumin. Brain Res. 2004;1014(1-2): 221-7.

36. Chirio D, Gallarate M, Peira E, Battaglia L, Muntoni E, Riganti C, et al. Positive-charged solid lipid nanoparticles as paclitaxel drug delivery system in glioblastoma treatment. Eur J Pharm Biopharm. 2014;88(3):746-58.

37. Cloughesy TF, Black KL. Pharmacological blood-brain barrier modification for selective drug delivery. J Neuro-Oncol. 1995;26(2):125-32.

38. Sang-Soo K, Hardford JB, Pirollo, Kathleen F, Chang EH. Effective treatment of glioblastoma requires crossing the bloodbrain barrier and targeting tumors including cancer stem cells: the promise of nanomedicine. Biochem Biophys Res Commun. 2015;468(3):485-9.

39. Blanco E, Shen H, Ferrari M. Principles of nanoparticle design for overcoming biological barriers to drug delivery. Nat Biotechnol. 2015;33(9):941-51.

40. Mikitsh JL, Chacko AM. Pathways for small molecule delivery to the central nervous system across the blood-brain barrier. Perspect Med Chem. 2014;6:11-24.

41. Mannhold R, Poda GI, Ostermann C, Tetko IV. Calculation of molecular lipophilicity: state-of-the-art and comparison of $\log \mathrm{p}$ methods on more than 96,000 compounds. J Pharm Sci. 2009;98(3):861-93.
42. Oldendorf WH, Hyman S, Braun LOS. Blood-brain barrier: penetration of morphine, codeine, heroin, and methadone after carotid injection. Science. 1972;178:984-6.

43. Kanazawa T, Kaneko M, Niide T, Akiyama F, Kakizaki S, Ibaraki $\mathrm{H}$, et al. Enhancement of nose-to-brain delivery of hydrophilic macromolecules with stearate- or polyethylene glycol-modified arginine-rich peptide. Int J Pharm. 2017;530(1-2):195-200.

44. Kokate A, Li X, Jasti B. Effect of drug lipophilicity and ionization on permeability across the buccal mucosa: a technical note. AAPS PharmSciTech. 2008;9(2):501-4.

45. Zhang Z, Zhan C. Receptor-mediated transportation through BBB. Brain Targeted Drug Delivery System [Internet] Elsevier. 2019:105-28 Available from: https://linkinghub.elsevier.com/ retrieve/pii/B9780128140017000056. Accessed 2019 May 30.

46. Lajoie JM, Shusta EV. Targeting receptor-mediated transport for delivery of biologics across the blood-brain barrier. Annu Rev Pharmacol Toxicol. 2015;55:613-31.

47. Gao H, Yang Z, Zhang S, Cao S, Pang Z, Yang X, et al. Gliomahoming peptide with a cell-penetrating effect for targeting delivery with enhanced glioma localization, penetration and suppression of glioma growth. J Control Release. 2013;172(3):921-8.

48. Johnsen KB, Burkhart A, Melander F, Kempen PJ, Vejlebo JB, Siupka P, et al. Targeting transferrin receptors at the blood-brain barrier improves the uptake of immunoliposomes and subsequent cargo transport into the brain parenchyma. Sci Rep. 2017;7(1):113.

49. Pulicherla KK, Verma MK. Targeting therapeutics across the blood brain barrier (bbb), prerequisite towards thrombolytic therapy for cerebrovascular disorders - an overview and advancements. AAPS PharmSciTech. 2015;16(2):223-33.

50. Voth B, Nagasawa DT, Pelargos PE, Chung LK, Ung N, Gopen Q, et al. Transferrin receptors and glioblastoma multiforme: current findings and potential for treatment. J Clin Neurosci. 2015;22(7): 1071-6.

51. Friden PM, Walus LR, Musso GF, Starzyk RM. Anti-transferrin receptor antibody and antibody-drug conjugates cross the bloodbrain barrier. Med Sci Nat. 1991;88(June):4771-5.

52. Kang T, Jiang M, Jiang D, Feng X, Yao J, Song Q, et al. Enhancing glioblastoma-specific penetration by functionalization of nanoparticles with an iron-mimic peptide targeting transferrin/ transferrin receptor complex. Mol Pharm. 2015;12(8):2947-61.

53. Veringa SJE, Biesmans D, van Vuurden DG, Jansen MHA, Wedekind LE, Horsman I, et al. In vitro drug response and efflux transporters associated with drug resistance in pediatric high grade glioma and diffuse intrinsic pontine glioma. PLoS One. 2013;8(4):e61512.

54. Miller DS. Regulation of $\mathrm{ABC}$ transporters at the blood-brain barrier. Clin Pharmacol Ther. 2015;97(4):395-403.

55. He Q, Liu J, Liang J, Liu X, Li W, Liu Z, et al. Towards improvements for penetrating the blood-brain barrier-recent progress from a material and pharmaceutical perspective. Cells. 2018;7(4):24.

56. Kelderman S, Schumacher TNM, Haanen JBAG. Acquired and intrinsic resistance in cancer immunotherapy. Mol Oncol. 2014;8(6):1132-9.

57. Holohan C, Van Schaeybroeck S, Longley DB, Johnston PG. Cancer drug resistance: an evolving paradigm. Nat Rev Cancer. 2013:13 (10):714-26.

58. Laramy JK, Kim M, Parrish KE, Sarkaria JN, Elmquist WF. Pharmacokinetic assessment of cooperative efflux of the multitargeted kinase inhibitor ponatinib across the blood-brain barrier. J Pharmacol Exp Ther. 2018 May;365(2):249-61.

59. Owens DE, Peppas NA. Opsonization, biodistribution and pharmacokinetics of polymeric nanoparticles. Int J Pharm. 2006;307: 93-102. 
60. Hume DA. The mononuclear phagocyte system. Curr Opin Immunol. 2006;18(1):49-53.

61. Nie S. Understanding and overcoming major barriers in cancer nanomedicine. Nanomedicine (London). 2010;5(4):523-8.

62. Lundqvist M, Augustsson C, Lilja M, Lundkvist K, Dahlbäck B, Linse $\mathrm{S}$, et al. The nanoparticle protein corona formed in human blood or human blood fractions. PLoS One. 2017;12(4):1-15.

63. Dean DA, Gottfried LF. In: Wei M, editor. Extracellular and Intracellular barriers to non-viral gene transfer, Novel Gene Therapy Approaches. Wei M, Good D, Eds.; Intech: 2013.

64. Jokerst JV, Lobovkina T, Zare RN, Gambhir SS. Nanoparticle PEGylation for imaging and therapy. Nanomedicine (London). 2011;6(4):715-28.

65. McErlean EM, McCrudden CM, McCarthy HO. Delivery of nucleic acids for cancer gene therapy: overcoming extra- and intra-cellular barriers. Ther Deliv. 2016;7(9):619-37.

66. Verhoef JJF, Anchordoquy TJ. Questioning the use of PEGylation for drug delivery. Drug Deliv Transl Res. 2013;3(6):499-503.

67. Morshed RA, Muroski ME, Dai Q, Wegscheid ML, Auffinger B, Yu D, et al. Cell-penetrating peptide-modified gold nanoparticles for the delivery of doxorubicin to brain metastatic breast cancer. Mol Pharm. 2016;13(6):1843-54.

68. Chan JM, Valencia PM, Zhang L, Langer R, Farokhzad OC. Polymeric nanoparticles for drug delivery. Methods Mol Biol. 2010;624:163-75.

69. Upreti M, Jyoti A, Sethi P. Tumor microenvironment and nanotherapeutics. Transl Cancer Res. 2013;2(4):309-19.

70. Yang Y, Yan Z, Wei D, Zhong J, Liu L, Zhang L, et al. Tumorpenetrating peptide functionalization enhances the antiglioblastoma effect of doxorubicin liposomes. Nanotechnology. 2013;24(40):405101

71. Nakamura Y, Mochida A, Choyke PL, Kobayashi H. Nanodrug delivery: is the enhanced permeability and retention effect sufficient for curing cancer? Bioconjug Chem. 2016;27(10):2225-38.

72. Stylianopoulos T, Martin JD, Chauhan VP, Jain SR, DiopFrimpong B, Bardeesy N, et al. Causes, consequences, and remedies for growth-induced solid stress in murine and human tumors. Proc Natl Acad Sci. 2012;109(38):15101-8.

73. Peck T, Hill S, Williams M. Drug passage across the cell membrane. Pharmacol Anaesth Intens Care, $3^{\text {rd }}$ Ed. Cambridge: Cambridge University Press; 2008: 1-7.

74. Hong R, Huang C, Tseng Y. Direct comparison of liposomal doxorubicin with or without polyethylene glycol coating in c-26 tumorbearing mice: is surface coating with polyethylene glycol beneficial? direct comparison of liposomal doxorubicin with or without polyethylene glycol coa. Clin Cancer Res. 1999;5(November): 3645-52.

75. Kessenbrock K, Plaks V, Werb Z. Matrix metalloproteinases: regulators of the tumor microenvironment. Cell. 2010;141(1):52-67.

76. Könnecke H, Bechmann I. The role of microglia and matrix metalloproteinases involvement in neuroinflammation and gliomas. Clin Dev Immunol. 2013;2013:914104-19.

77. Bruun J, Larsen TB, Jolck RI, Eliasen R, Holm R, Gjetting T, et al. Investigation of enzyme-sensitive lipid nanoparticles for delivery of siRNA to blood - brain barrier and glioma cells. Int $\mathrm{J}$ Nanomedicine. 2015;10:5995-6008.

78. Kulkarni PS, Haldar MK, Nahire RR, Katti P, Ambre AH, Muhonen WW, et al. MMP-9 responsive PEG cleavable nanovesicles for efficient delivery of chemotherapeutics to pancreatic cancer. Mol Pharm. 2014;11(7):2390-9.

79. Estrella V, Chen T, Lloyd M, Wojtkowiak J, Cornnell HH, Ibrahim-Hashim A, et al. Acidity generated by the tumor microenvironment drives local invasion. Cancer Res. 2013;73(5):152435.

80. Zhang L, Wang Y, Yang Y, Liu Y, Ruan S, Zhang Q, et al. High tumor penetration of paclitaxel loaded $\mathrm{pH}$ sensitive cleavable liposomes by depletion of tumor collagen i in breast cancer. ACS Appl Mater Interfaces. 2015;7(18):9691-701.

81. Yi X. Kabanov A V. Brain delivery of proteins via their fatty acid and block copolymer modifications. J Drug Target. 2013;21(10): 940-55.

82. U.S. National Library of Medicine. ClinicalTrials.gov [Internet]. U.S. National Institute of Health. 2018 [cited 2019 Sep 2]. Available from: https://clinicaltrials.gov/ct2/home

83. Aghi M, Rabkin S. Viral vectors as therapeutic agents for glioblastoma. Curr Opin Mol Ther. 2005;7(5):419-30.

84. Kaufmann JK, Chiocca EA. Glioma virus therapies between bench and bedside. Neuro-Oncology. 2014;16(3):334-51.

85. Chao CN, Yang YH, Wu MS, Chou MC, Fang CY, Lin MC, et al. Gene therapy for human glioblastoma using neurotropic JC viruslike particles as a gene delivery vector. Sci Rep. 2018;8(1):1-11.

86. Raper SE, Chirmule N, Lee FS, Wivel NA, Bagg A, Gao G, et al. Fatal systemic inflammatory response syndrome in a ornithine transcarbamylase deficient patient following adenoviral gene transfer. Mol Genet Metab. 2003;80(1-2):148-58.

87. Rauch S, Jasny E, Schmidt KE, Petsch B. New vaccine technologies to combat outbreak situations. Front Immunol. 2018;9:1963.

88. Carvalho M, Sepodes B, Martins AP. Regulatory and scientific advancements in gene therapy: state-of-the-art of clinical applications and of the supporting european regulatory framework. Front Med. 2017;4:182.

89. McErlean EM, McCrudden CM, McCarthy HO. Multifunctional delivery systems for cancer gene therapy. Gene Therapy Principles and Challenges: InTech; 2015: 57104.

90. Guo X, Huang L. Recent advances in non-viral vectors for gene delivery. Acc Chem Res. 2012;45(7):971-9.

91. Ramamoorth M. Non viral vectors in gene therapy- an overview. J Clin Diagn Res. 2015; 9:GE01-GE06.

92. Xu L, Anchordoquy TJ. Drug delivery trends in clinical trials and translational medicine: challenges and opportunities in the delivery of nucleic acid-based therapeutics. J Pharm Sci. 2011;100(1): $38-52$.

93. Kristensen M, Birch D, Nielsen HM. Applications and challenges for use of cell-penetrating peptides as delivery vectors for peptide and protein cargos. Int J Mol Sci. 2016;17(2):185-202.

94. Temsamani J, Vidal P, Temsamani J. The use of cell-penetrating peptides for drug delivery. Drug Discov Today. 2004;9(23):10129.

95. Walrant A, Correia I, Jiao CY, Lequin O, Bent EH, Goasdou N, et al. Different membrane behaviour and cellular uptake of three basic arginine-rich peptides. Biochim Biophys Acta Biomembr. 2011;1808(1):382-93.

96. Mitchell DJ, Steinman L, Kim DT, Fathman CG, Rothbard JB. Polyarginine enters cells more efficiently than other polycationic homopolymers. J Pept Res. 2000;56(5):318-25.

97. McCarthy HO, McCaffrey J, McCrudden CM, Zholobenko A, Ali AA, McBride JW, et al. Development and characterization of selfassembling nanoparticles using a bio-inspired amphipathic peptide for gene delivery. J Control Release. 2014;189:141-9.

98. Heitz F, Morris MC, Divita G. Twenty years of cell - penetrating peptides: from molecular mechanisms to therapeutics. Br J Pharmacol. 2009;157(July 2008):195-206.

99. Li W, Nicol F, Szoka FC. GALA: a designed synthetic pHresponsive amphipathic peptide with applications in drug and gene delivery. Adv Drug Deliv Rev. 2004;56(7):967-85.

100. Gujrati M, Malamas A, Shin T, Jin E, Sun Y, Lu Z. Multifunctional cationic lipid-based nanoparticles facilitate endosomal escape and reduction-triggered cytosolic siRNA release. 2014

101. Bennett R, Yakkundi A, McKeen HD, McClements L, McKeogh TJ, McCrudden CM, et al. RALA-mediated delivery of FKBPL nucleic acid therapeutics. Nanomedicine (London). 2015;10:1-30. 
102. McCrudden CM, McBride JW, McCaffrey J, Ali AA, Dunne NJ, Kett VL, et al. Systemic RALA/iNOS nanoparticles: a potent gene therapy for metastatic breast cancer coupled as a biomarker of treatment. Mol Ther - Nucleic Acids. 2017;6(November 2016): 249-58.

103. Sathy BN, Olvera D, Gonzalez-Fernandez T, Cunniffe GM, Pentlavalli S, Chambers P, et al. RALA complexed $\alpha$-TCP nanoparticle delivery to mesenchymal stem cells induces bone formation in tissue engineered constructs in vitro and in vivo. J Mater Chem B. 2017;5:1753-64.

104. Massey AS, Pentlavalli S, Cunningham R, McCrudden CM, McErlean EM, Redpath P, et al. Potentiating the anticancer properties of bisphosphonates by nanocomplexation with the cationic amphipathic peptide, RALA. Mol Pharm. 2016;13(4):1217-28.

105. Cole G, McCaffrey J, Ali AA, McBride JW, McCrudden CM, Vincente-Perez EM, et al. Dissolving microneedles for DNA vaccination: improving functionality via polymer characterization and RALA complexation. Hum Vaccines Immunother. 2017;13(1): $50-62$.
106. Fang Y, Jiang Y, Zou Y, Meng F, Zhang J, Deng C, et al. Targeted glioma chemotherapy by cyclic RGD peptide-functionalized reversibly core-crosslinked multifunctional poly(ethylene glycol)-bpoly( $\varepsilon$-caprolactone) micelles. Acta Biomater. 2017;50:396-406.

107. Salazar-Ramiro A, Ramfrez-Ortego D, Pérez de la Cruz V, Hérnandez-Pedro NY, Gonzalez-Esquivel DF, Sotelo J et al. Role of Redox Status in Development of Glioblastoma. Front Immunol. 2016;7:156.

108. Mo J, He L, Ma B, Chen T. Tailoring particle size of mesoporous silica nanosystem to antagonize glioblastoma and overcome blood-brain barrier. ACS Appl Mater Interfaces. 2016;8(11): 6811-25.

109. Kong L, Qiu J, Sun W, Yang J, Shen M, Wang L, et al. Multifunctional PEI-entrapped gold nanoparticles enable efficient delivery of therapeutic siRNA into glioblastoma cells. Biomater Sci R Soc Chem. 2017;5(2):258-66.

Publisher's note Springer Nature remains neutral with regard to jurisdictional claims in published maps and institutional affiliations. 